\title{
A more complete version of the World Glacier Inventory
}

\author{
J. Graham COGLEY \\ Department of Geography, Trent University, Peterborough, Ontario K9J 7G6, Canada \\ E-mail: gcogley@trentu.ca
}

\begin{abstract}
The World Glacier Inventory (WGI) was conceived half a century ago as an activity to be completed during the International Geophysical Year, 1957/58. It consisted until very recently of nearly 70000 glacier records covering slightly less than one-quarter of the glacier ice outside the ice sheets. A complete WGI must be a compromise if it is to be available and usable soon. A more complete version, called WGI-XF, is available and usable now and contains records for just over 131000 glaciers and nearly half of the global extent of ice. The additional glaciers come mainly from the assimilation of existing inventories but also from rescuing inventories that have been lost and from new inventories in Canada and the Subantarctic. In WGI-XF, the XF stands for 'extended format', flagging the fact that WGI-XF conforms to a set of explicit specifications which enhance usefulness by eliminating low-level inconsistencies. Two important features are nominal glaciers and glacier complexes. A nominal glacier, of which there are about 5000 in WGI-XF, is one about which little is known other than its existence and approximate location. A glacier complex is one or more contiguous glaciers. This term embodies the idea, which is not new, that inventories can be preliminary, based upon vector outlines which await subdivision by trained glaciologists. Many regional studies have found that measurements of changes in single glaciers require accurate work and painstaking quality control. WGI-XF is not assuredly reliable as a source for such detailed work, but there are several other subjects in which less detail would be a price worth paying for more complete coverage. Incomplete information about the dates of imagery and maps is a hindrance to analysis, and the recovery of dates from metadata should have high priority.
\end{abstract}

\section{INTRODUCTION}

I present here an enlarged version of the World Glacier Inventory (WGI), in which several recently published, some rescued and some new regional inventories are assimilated into the original material. The new inventory has an extended format which promotes ease of use by prescribing low-level details of data storage, giving it its acronym, WGIXF. At the time of writing, WGI-XF contains records for 131000 glaciers.

It is a postulate of the present work that fewer details and coarser resolution would be a price worth paying for a more complete inventory if it were available soon. This postulate is realized substantially in the shape of two concepts: that of the nominal glacier, which is a glacier about which little is known other than its existence and approximate location; and that of the glacier complex, which is a collection of contiguous glaciers. The latter concept, that inventories can be preliminary, based (nowadays) upon vector outlines which await subdivision by trained glaciologists, is at least as old as the guidelines of Scherler (1983).

The idea of the WGI is now more than 50 years old, but in its most complete form today the WGI covers somewhat less than one-third of the glacier ice outside the ice sheets. WGIXF covers nearly half of the ice, which is a step forward but still leaves as much work to do as has been accomplished over the past half-century. A complete WGI, apart from making it easy to answer simple questions of fact, would make it possible to tackle more substantial questions which at present can scarcely be attempted.

In the following sections I describe the compilation and the principles of the design of WGI-XF; illustrate the details of the extended format with highlights; discuss some of the advantages and limitations of WGI-XF; and suggest some avenues for further development of the format and more rapid assimilation of those glaciers which are not yet part of any inventory.

\section{SOURCES}

The core of WGI-XF is the WGI as available from the US National Snow and Ice Data Center (NSIDC), Boulder, CO, which in turn consists of the WGI proper (WGMS, 1989) and the Eurasian Glacier Inventory (EGl; Bedford and Haggerty, 1996). These and other sources are summarized in Table 1 and Figure 1.

Several regional inventories documented in WGMS (1989) are not in the NSIDC version (see Table 1, last footnote). It was possible to rescue many but not all of the lost records. The largest sets of rescued data are for southern Peru and the Brooks Range, Alaska. The latter inventory survived only as a computer printout in the possession of M.B. Dyurgerov, to whom I am grateful for the loan of the paper copy.

The EGI's wrong romanization of Cyrillic letters denoting glacier aspects was corrected, and some 2800 omitted glaciers in central Asia and elsewhere were added from original Russian-language sources.

The largest single newly assimilated source was the Glacier Inventory of China. Part of this inventory is in the EGI. The remaining elements were obtained from the internet. One of the most notable achievements in Table 1 is that of the International Centre for Integrated Mountain Development, Kathmandu, Nepal (ICIMOD; e.g. Mool and others, 2001, Sah and others, 2005), a developing-country organization which has inventoried nearly all of the Himalaya, such that when pooled with Chinese and Indian 
Table 1. Sources and contents of WGI-XF. No.: source number; see Cogley (2008a) for a full list. For some locations, the numbers and areas reflect withholding of records duplicated in other sources

\begin{tabular}{|c|c|c|c|c|}
\hline No. & Source & Locations & $\begin{array}{l}\text { Number of } \\
\text { glaciers }\end{array}$ & $\begin{array}{l}\text { Area } \\
\mathrm{km}^{2}\end{array}$ \\
\hline 1,4 & World Glacier Monitoring Service (NSIDC) & Global & 35969 & 72542 \\
\hline 2 & Institute of Geography, Russian Academy of Sciences, Moscow (NSIDC) & Former USSR & 20723 & 75763 \\
\hline 3 & World Data Center - Glaciology, Lanzhou (NSIDC) & Northern China & 12183 & 11470 \\
\hline 5 & Greenland Geological Survey, Copenhagen (NSIDC) & Southwest Greenland & 5032 & 14555 \\
\hline \multirow[t]{5}{*}{6} & ICIMOD, Kathmandu & Pakistan & 5081 & 14359 \\
\hline & & Himachal Pradesh & 2231 & 3637 \\
\hline & & Uttarakhand & 1460 & 4042 \\
\hline & & Nepal & 3249 & 5321 \\
\hline & & Bhutan & 602 & 909 \\
\hline 7 & World Data Center - Glaciology, Lanzhou* & Southern China & 34063 & 48388 \\
\hline 8 & Garín (1987) & Northern Chile & 88 & 161 \\
\hline \multirow[t]{3}{*}{9} & Hagen and others (1993) & Jan Mayen & 20 & 112 \\
\hline & & Eastern Svalbard & 192 & 14692 \\
\hline & & Svalbard (nominal) & 1237 & 413 \\
\hline 10-13 & Trent University & Subantarctic ${ }^{\dagger}$ & 562 & 5850 \\
\hline \multirow[t]{2}{*}{14} & Trent University ${ }^{\ddagger}$ & Eastern Yukon, Northwest Territories & 336 & $\mathrm{n} / \mathrm{a}$ \\
\hline & & Labrador & 16 & $\mathrm{n} / \mathrm{a}$ \\
\hline 32 & Trent University ${ }^{\ddagger}$ & Baffin Island, Bylot Island & 1420 & 42325 \\
\hline 15 & US Geological Survey, Tacoma, WA & Brooks Range, Alaskall & 1000 & 720 \\
\hline 16 & Ames and others (1989) & Southern Peru" & 1365 & 912 \\
\hline \multirow[t]{3}{*}{17} & Kaul (1999) & Kashmir (small sample) & 133 & 94 \\
\hline & & Himachal Pradesh (part) & 224 & 420 \\
\hline & & Sikkim & 449 & 705 \\
\hline 18 & Trent University & Former USSR ${ }^{\S}$ & 2835 & 1951 \\
\hline 19 & Sedov (1997) & Tajgonos peninsula, eastern Siberia & 14 & 1.9 \\
\hline 20 & Gellatly and others (1994) & Abruzzi, Italy & 1 & 0.02 \\
\hline 21 & WGMS (1993) & Germany $\|$ & 5 & 1.0 \\
\hline 22 & Lorenzo (1964); White (2002) & Mexico & 23 & 14.6 \\
\hline 23 & Allison and Peterson (1989) & Indonesiall & 8 & 7.5 \\
\hline $24-30$ & Several published papers & Patagonia (incomplete) & 504 & 16463 \\
\hline 31 & Calkin and others (1998) & Kigluaik Mountains, Alaska & 3 & 0.5 \\
\hline
\end{tabular}

Note: n/a: not available.

*Obtained from http://wdcdgg.westgis.ac.cn/DATABASE/Glacier/glacier_inventory.asp, October 2006.

${ }^{\dagger}$ South Georgia not yet inventoried.

${ }^{\ddagger}$ Glacier complexes only; areas $\left(\sim 10^{3} \mathrm{~km}^{2}\right.$ in total) not yet available from source 14 .

§Parts not in Eurasian Glacier Inventory (source 2 ).

Numbers exclude $100729 \mathrm{~km}^{2}$ in 267 sectors of the ice sheet.

"Information lost from the WGI and rescued during the current work.

information the only gap in coverage between the Hindu Kush and Burma is now in the Indian part of Kashmir. However, considerable reformatting was involved in readying the ICIMOD data for inclusion in WGI-XF, as well as some conjecture when interpreting the accompanying documentation.

These additions, and several smaller ones, solve the problem of non-submission of regional inventories to central repositories, at least as far as published, accessible work is concerned.

New inventories in progress at Trent University have yielded a substantial number of new records, all derived from maps rather than imagery. Coverage of eastern Yukon and adjoining parts of the Northwest Territories by vector outlines and digital elevation models, from source maps at $1: 50000$ scale, is complete and freely available. This littlestudied region, inventoried in part by Ommanney (1993), has some 1300 glaciers covering more than $700 \mathrm{~km}^{2}$. At present they appear in WGI-XF only as glacier complexes. Baffin Island and Bylot Island have also been inventoried from digital map material, but here the map scale of $1: 250000$ means that the outlines are quite generalized. As yet the information for this region, principally areas, is limited. An inventory of the Subantarctic islands, which is nearing completion, yields an inventoried area of $5850 \mathrm{~km}^{2}$, with an estimated $2000 \mathrm{~km}^{2}$ in South Georgia yet to be analyzed.

Extensive measures for quality control were taken while assimilating the various source inventories. These included tests of the consistency of entries in related data fields, study of source documents to establish the meaning and relevance of non-standard terms, and screening for duplicates.

WGI-XF is more complete than the WGI housed at NSIDC, but the still-to-do bands in Figure 1 show that much work remains. Antarctica is shown separately because it is the largest place where an inventory of glacier complexes could yield valuable results in return for moderate effort. Suitable digital outlines are already available for the entire area, although information on elevations is less well resolved. Nearly all of the rest-of-world band in Figure 1 is 


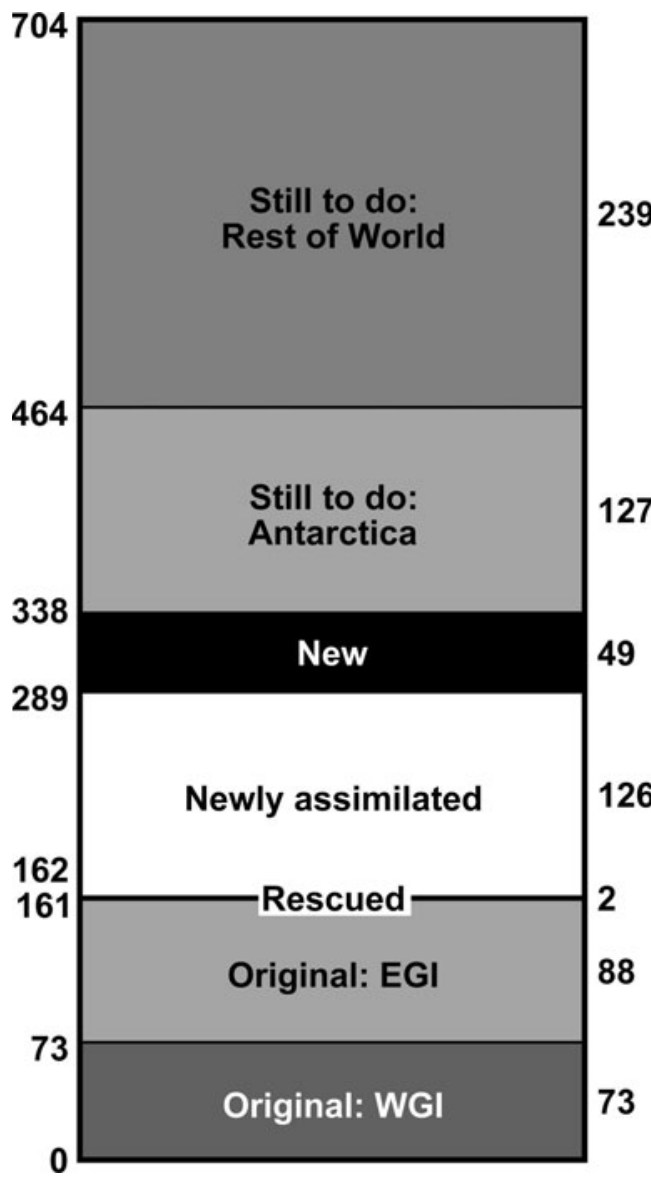

Fig. 1. Status of the WGI, 2008, in terms of glacierized area in $10^{3} \mathrm{~km}^{2}$ (at right; numbers at left are cumulative). Total area, with uncertainty estimated as $\pm 56 \times 10^{3} \mathrm{~km}^{2}$, is from de Woul (2008). The Antarctic area, from de Woul's analysis of version 4.1 of the Antarctic Digital Database (ADD Consortium, http://www.add. scar.org:8080/add/index.jsp), extends to $79^{\circ} \mathrm{S}$ but excludes the ice sheet, ice rises, and islands assigned in WGI-XF to the Subantarctic.

in North America, although substantial parts of this gap are already in the Global Land Ice Measurements from Space (GLIMS) database, from which they await assimilation into WGI-XF. Elsewhere the largest gaps are in Patagonia, Kashmir and Afghanistan (Table 2). Regions with inadequate source materials are few, which means that completion of the WGI, at least to the level of glacier complexes, is mainly a matter of supporting the necessary labour rather than addressing technical challenges. Work in which the best possible accuracy is desirable will take longer.

\section{PRINCIPLES OF DESIGN}

WGI-XF has been designed to be as flat as possible and to have a format as unambiguous as possible. Flatness, in the jargon of software engineering, means that the data are not organized hierarchically and that the data records are mutually independent. These attributes imply in turn that data will be easy to input into computer programs and to treat as a basis for the development of more sophisticated uses such as structured queries and a range of applications in geographic information science. As an example of the latter, many of the glacier records in WGI-XF point, via the IdCode field, to files which contain vector outlines of the glaciers. These files are not formally a part of WGI-XF, in which

Table 2. Glaciers not yet inventoried, or not yet assimilated into WGI-XF. Estimates of area are from WGMS (1989) or from textbooks; some are rough. Availability: No - maps not available or not adequate; $\mathrm{Y}$ - maps available from governmental or commercial sources ( $v$ : vector format; $r$ : raster format; $p$ : paper format); GLIMS - inventory available in the GLIMS database.

Region

Area

$\mathrm{km}^{2}$

South America

Patagonia

Rest

North America

Western North America (Canada)

Western North America (USA)

Queen Elizabeth Islands

Greenland

Europe

Iceland

Asia

Chukotka

Mongolia

Burma

Kashmir (India)

Afghanistan

Iran/Turkey

Subantarctic

South Georgia

Antarctica

Peripheral ice bodies

$\begin{array}{rc}4000 & \text { No } \\ 500 & \text { No } \\ & \\ 38000 & \text { Yv } \\ 74000 & \text { Yv } \\ 84000 & \text { Yv } \\ 40000 & ? \mathrm{Yv} \\ & \\ 11000 & \text { GLIMS } \\ & \\ 20 & ? \mathrm{No} \\ 600 & \mathrm{Yr} \\ 10 & \mathrm{No} \\ 4000 & \mathrm{Yr} \\ 1000 & ? \mathrm{No} \\ 40 & ? \mathrm{No} \\ 2000 & \mathrm{Yp} \\ 127000 & \mathrm{Yv}\end{array}$

respect it differs from GLIMS (Raup and others, 2007). GLIMS is a venture at a higher level of organization, in which the linkages between data elements are prescribed explicitly, but WGI-XF is supported implicitly by a number of related data elements. In addition to glacier outlines, these include, with varying completeness, outlines of hydrographic regions, lists of data sources and country codes, and hypsometric tables.

For a format to be free of ambiguity it is necessary not only that the quantities which it stores be defined clearly, but also that the constraints on what may be stored be set out explicitly. The original specifications of the WGI (UNESCO/ IASH, 1970; Müller and others, 1977; Müller, 1978; Scherler, 1983) were not free of ambiguity, and changed repeatedly during the most active period of data collection and assembly. I have taken these facts, and the inconsistent adherence to specifications documented by Evans (2006), as licence to build on the original definitions by both making them more explicit and extending and clarifying them.

\section{EXTENDED FORMAT}

For the benefit of fellow-students who may wish to use it, the format of WGI-XF is illustrated briefly here. It is specified exhaustively by Cogley (2008a). In accordance with the principles of the previous section, each glacier is represented by one inventory record of fixed length (420 characters in release 1) containing 8-bit ASCII characters of the Basic Latin/Latin-1 set of the Unicode standard. In fact the 7-bit ASCII character set prevails except in the Name and Locale fields, in which letters of the multinational Latin character set may be found. Each record has 54 fields 
of fixed position, width, number of decimal digits, and 'type'. There are six of these types: glacier IdCode, character (free text), character (date), real (coordinate), real (scalar) and integer.

All numbers and codes which represent the concepts 'missing' or 'unknown' have been standardized, although it is not possible to separate these concepts where the corresponding WGI codes are overloaded. For example, the six digits of the WGI Classification code, which in WGI-XF have become integers occupying two-character fields, can represent 'missing' or 'unknown' (which are not synonyms) and also 'normal or miscellaneous' when they have the value 0 .

Only some of the extensions of the original structure of the WGI are described here. In each case the purpose of the extension, beyond providing useful information, is to eliminate inconsistencies of format which can slow analysis down.

The first field, the 12-character IdCode, is the same as in WGI except that all country codes consist of two letters. In WGI, all country codes consisting of a letter followed by a blank, such as ' $N$ ' for Norway, have lost their trailing blanks. For this and other reasons, not all codes in WGI have 12 characters. Glaciers in countries of the former Soviet Union still have the country code $\mathrm{SU}$, but it is planned to remedy this.

All dates are in the prescribed eight-numeral format YYYYMMDD, with leading zeros required. For dates of maps, imagery and tongue activity a two-date range is prescribed, permitting the assessment of uncertainty in times and durations.

Some classification fields have been extended. For example, PClass, the field corresponding to digit 1 of the WGI Classification (primary classification), has a value representing 'ice stream' (Rau and others, 2005), and also a value for 'glacier complex'. FrontChar, representing digit 3 (frontal characteristics), has new values for lacustrine calving, marine calving (floating) and marine calving (grounded). In addition, there are new integer fields named DebrisCover, Calving, and Floating, intended to reduce ambiguity by reducing the overloading and interdependence of the other Classification digits. A field for a Surging code is planned but has not yet been implemented.

The glacier Name field is as in WGI, but the Unicode names given in the Glacier Inventory of China have been romanized with the help of the public-domain dictionary CEDICT of P.A. Denisowski (http://www.mandarintools. com). The new Locale field contains names of maps, mountains, mountain ranges and the like.

The OldNumber field contains the identification code of the glacier in the inventory from which it was assimilated. A considerable amount of recoding was necessary in the construction of WGI-XF. For example, it is exceptional for coding schemes to be in harmony across national frontiers, and several of these conflicts have been rectified. OldNumber provides backward accessibility in case it is necessary to return to the source inventory.

The CheckFlags field contains an integer which consists of 1-bit numbers flagging unresolvable internal inconsistencies in the glacier record. Minimum elevations exceeding maximum elevations, and map coordinates more than $5 \mathrm{~km}$ distant from geographical coordinates, are examples. The CheckFlags field has been used during compilation to correct many hundreds of typographical errors, most of them obvious transpositions of digits. Undoubtedly, many such errors have not been detected, but those which have can now be checked by the analyst.

Two of the flags mark nominal locations and nominal areas, and allow the inclusion of glaciers which are recorded only collectively in source inventories. Typically, a region is reported as containing $N$ glaciers smaller than $X \mathrm{~km}^{2}$ with a total area of $S \mathrm{~km}^{2}$, and in WGI-XF each of these nominal glaciers is assigned the basin centroid as location and the quantity $S / N$ as area. There are such glaciers in the WGI from Bolivia and Colombia, and nominal glaciers have been added in WGI-XF for Svalbard and Jan Mayen, where they account for $1.1 \%$ of total glacierized area, and the former Soviet Union, where as yet they have been added for only a small proportion of basins. Nominal glaciers are a partial corrective for the problem of truncated number and size distributions.

WGI-XF release 1 is available from http://www.trentu.ca/ geography/glaciology/glaciology.htm as a 4 Mbyte compressed (.zip) file which expands to 53 Mbytes. The records are sorted by IdCode, which in effect means by country, then by hydrographic region and finally by glacier number. A comma-separated-value version is available, with commas taking the place of blanks in the canonical version to facilitate input into programs such as Microsoft Excel.

\section{DISCUSSION}

\section{Regionalization}

Much regional inventory work leaves incomplete the task of assigning the hydrographic region codes that are the basis for the WGI's identification of individual glaciers. Digitizing hydrographic boundaries and constructing a coherent numbering scheme are time-consuming, and the latter task is difficult when attempted 'from the bottom up'. Yet some scheme of regionalization, preferably available to all in digital format, is highly desirable for global-scale studies of glaciers. Several studies have drawn attention to difficulties in applying the Horton-Strahler basin ordering scheme to glacierized regions, although it has not always been appreciated that a strict application is not necessary and that the essential point is to cover the terrain completely (and exactly once per point) in such a way that each glacier can be associated with a destination for its meltwater. With complete coverage, the assignment of region codes to glaciers becomes a trivial point-in-polygon problem, although it is demanding in terms of the horizontal accuracy of the region outlines because glaciers tend to lie on drainage divides. I have made some progress in building hierarchies of consistently coded hydrographic regions, but much remains to be done and a greater proportion of total effort should be given to this task.

A related task which would eventually repay effort would be to construct a set of agreed topographic regions which would be, loosely speaking, 'orthogonal' to the set of hydrographic regions. It is often convenient to study single mountain ranges rather than the several basins to which they drain. It would also be worth adding a field to represent the political dimension more adequately than now, for sub-national political subdivisions are important in waterresources management.

Another form of regionalization is to assign ice-covered areas to cells in a geographical grid. GGHYDRO (Cogley, 2003) is a dataset containing, among other things, extents of 


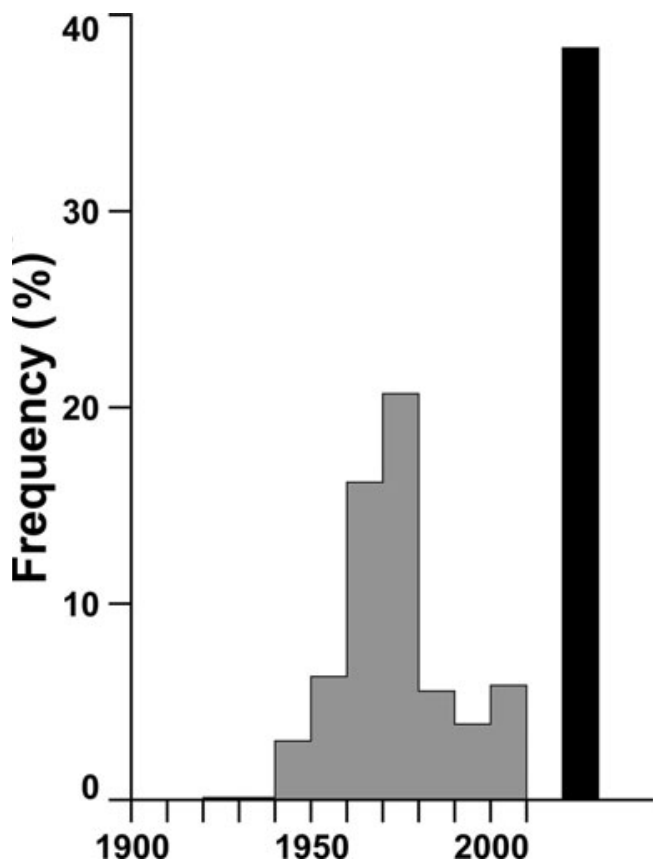

Fig. 2. The frequency distribution of the PhotoDate field in WGI-XF. Of 131396 records, 38\% have no date (black bar at right).

glacier ice at $1^{\circ} \times 1^{\circ}$ resolution. It has been used in a number of glaciological investigations (e.g. Kaser and others, 2006; Raper and Braithwaite, 2006). Remarkably, it is the only such gridded dataset, but it is 25 years old and was created by sparse sampling of 1:1000000 scale maps. WGI-XF will be valuable as a basis for improving the accuracy of this grid.

\section{Analysis of change}

The WGI was not conceived primarily as a tool for the analysis of change. At an early stage it was described as a snapshot of the world's glaciers at a time in the late 20th century. Recent studies (e.g. Andreassen and others, 2008) show clearly that glacier-by-glacier analysis of change requires painstaking, accurate work to match glaciers between earlier and later inventories. It is, however, reasonable to try to compare inventories at the regional level. There are two constraints on the direct use of WGI-XF in this context: the accuracy of inventory dates and the accuracy of estimates of regional ice-covered area.

Figure 2 summarizes the distribution of photo dates in WGI-XF. A similar picture, not shown, appears for map dates. There is a pronounced maximum of source dates in the 1970s, but the distribution is quite broad. More significantly, fewer than two-thirds of the inventory records have date information. To compound this problem, about one-eighth have dates which are in the form of ranges of years. These gaps in the documentation of simple facts arise because most topographic maps are not precise enough as sources of dates, and the laboriousness of inventory work makes it attractive for investigators to save time by not resorting to unpublished lists of air-photographic flights. Nevertheless, the need for a historical fixed point in studies of glacier change will grow rather than diminish, and retrospective efforts to sharpen the focus of the snapshot will always be worthwhile. In future it should be regarded as essential to record the date or date range of the survey, glacier by glacier, to at least the nearest month.

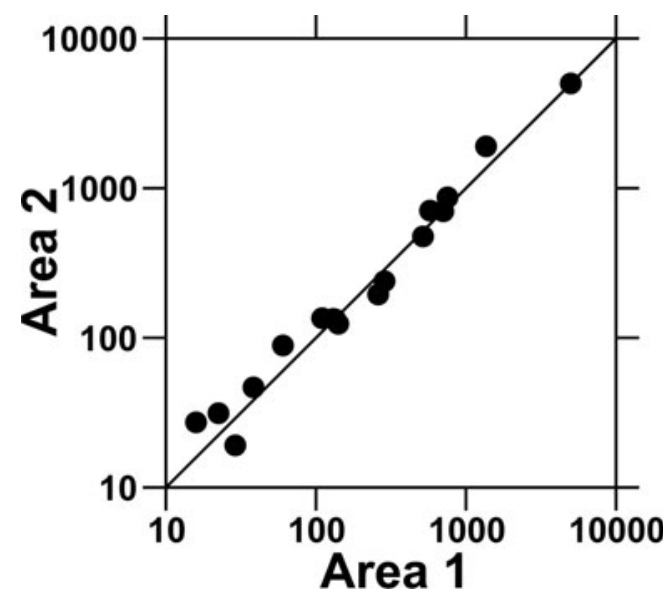

Fig. 3. Areas covered by ice $\left(\mathrm{km}^{2}\right)$ as estimated by duplicate regional inventories. In each case, inventory 1 was assimilated into WGI-XF and inventory 2 was withheld.

Some regions have been inventoried two or even three times by different workers, making it possible to estimate accuracy by treating these duplicates statistically as replicates. (Inventories are duplicates if they are based on similar or identical sources of approximately the same date. A repeated inventory is not the same thing.) If the regions are known to be the same, we can be confident that the duplicates ought, for example, to give the same aggregate ice-covered area. Figure 3 compares aggregate areas for 17 duplicate regional inventories, showing that agreement is generally good. The standard error of the difference ranges from $0.2 \%$ to $27 \%$, with nine errors less than $10 \%$. However, three are $20 \%$ or greater; in each case it is probable that one source treats debris cover more accurately than the other. The point is not whether such explanations can be found for large differences, but that this distribution of errors is likely to be typical. If so, WGI-XF is a repository of information which may or may not be appropriate for analyzing glacier shrinkage. Careful appraisal is required, for regional shrinkage rates observed in special-purpose studies are of the order of $-0.2 \% \mathrm{a}^{-1}$ and seldom exceed $-1 \% \mathrm{a}^{-1}$ (Cogley, 2008b).

\section{CONCLUDING REMARKS}

There is unavoidable tension between the need for better accuracy, on which admirable progress has been made by members of the GLIMS consortium, and the need for a complete inventory of the world's glaciers, on which progress, though now accelerating, has been slow. More careful work means later completion. The two aims are not incompatible, however, if two of the leading original themes of the WGI are acknowledged: the inventory should be expected to evolve in content and structure, and regional inventories may vary in detail and accuracy.

Further work is needed on several aspects of the content and structure of WGI-XF, such as reduction of the ambiguity which persists in the original specifications of WGI content, and the retrieval of fuller and better information about survey dates. One improvement not mentioned above is related to the need to accommodate repeated inventories. In this regard, the WGI specifies both a map date and a photo date. Ease of sorting and grouping will probably dictate a 
reordering of the WGI-XF fields such that the chosen date, preferably the photo date, follows the IdCode. But among planned future improvements the most useful may be the provision of a complete set of consistent hydrographic regions, to be supplemented by an orthogonal set of topographic regions. This is an unlikely outcome of the work of regional investigators because it needs to be done from the top down.

To judge from the experience of creating WGI-XF, the best way to complete the WGI quickly is to concentrate on the most essential data elements (location, date and area, followed probably by minimum and maximum elevation, length and width) and to pursue aggressively the use of available digital versions of maps of the regions to be inventoried. Most of these regions are in North America, and most of the maps are freely available not just as rasters but as digital linework. Therefore this is not an unreasonable programme, and the groundwork for it is already being laid (e.g. Schiefer and others, 2008). The inventory of Baffin Island and Bylot Island listed in Table 1 is an example of what can be achieved quickly. Subdivision of glacier complexes into glaciers, and acquisition of elevations from digital data, represent a second stage. The final stage, a full inventory, may remain a distant goal, but the rapid completion of subregional inventories (e.g. Svoboda and Paul, 2009) is a hopeful sign.

\section{ACKNOWLEDGEMENTS}

Among the many who have assisted with the assembly of information for WGI-XF, I thank in particular S. Bosnell (Inter Library Loan Office) and B. Znamirowski (Map Library) of Trent University. I am grateful to R. Barry for inviting me to attend the Workshop on Assessing Global Glacier Recession in Boulder in March 2003, which was the stimulus for this work.

\section{REFERENCES}

Allison, I. and J.A. Peterson. 1989. Glaciers of Irian Jaya, Indonesia. In Williams, R.S., Jr and J.G. Ferrigno, eds. Satellite image atlas of glaciers of the world. Denver, CO, US Geological Survey, H1-H20. (USGS Professional Paper 1386-H.)

Ames, A. and 7 others. 1989. Inventario de glaciares del Perú. Segunda parte. Huaraz, Hidrandina S.A.

Andreassen, L.M., F. Paul, A. Kääb and J.E. Hausberg. 2008. Landsat-derived glacier inventory for Jotunheimen, Norway, and deduced glacier changes since the 1930s. Cryosphere, 2(2), $131-145$.

Bedford, D. and C. Haggerty. 1996. New digitized glacier inventory for the former Soviet Union and China. Earth Syst. Monitor, 6(3), 8-10.

Calkin, P.E., D.S. Kaufman, B.J. Przybyl, W.B. Whitford and B.J. Peck. 1998. Glacier regimes, periglacial landforms, and Holocene climate change in the Kigluaik Mountains, Seward Peninsula, Alaska, U.S.A. Arct. Alp. Res., 30(2), 154-165.

Cogley, J.G. 2003. GGHYDRO - Global Hydrographic Data, Release 2.3. Peterborough, Ont., Trent University. Department of Geography. (Trent Technical Note, 2003-1.)

Cogley, J.G. 2008a. Extended Format for the World Glacier Inventory. Peterborough, Ont., Trent University. Department of Geography. (Trent Technical Note, 2005-1, revised 2008.)

Cogley, J.G. 2008b. Measured rates of glacier shrinkage. Geophys. Res. Abstr. 10, 11595. (www.cosis.net/abstracts/EGU2008/ 11595/EGU2008-A-11595.pdf).
De Woul, M. 2008. Response of glaciers to climate change: mass balance sensitivity, sea level rise and runoff. (PhD thesis, Stockholm University.)

Garín, C. 1987. Inventario de glaciares de los Andes Chilenos desde los $18^{\circ}$ a los $32^{\circ}$ de latitud sur. Rev. Geogr. Norte Grande, 14, 35-48.

Gellatly, A.F., C. Smiraglia, J.M. Grove and R. Latham. 1994. Recent variations of Ghiacciaio del Calderone, Abruzzi, Italy. J. Glaciol., 40(136), 486-490.

Hagen, J.O., O. Liestøl, E. Roland and T. Jørgensen. 1993. Glacier atlas of Svalbard and Jan Mayen. Nor. Polarinst. Medd. 129.

Kaser, G., J.G. Cogley, M.B. Dyurgerov, M.F. Meier and A. Ohmura. 2006. Mass balance of glaciers and ice caps: consensus estimates for 1961-2004. Geophys. Res. Lett., 33(19), L19501. (10.1029/2006GL027511.)

Kaul, M.K., ed. 1999. Inventory of the Himalayan Glaciers: a contribution to the International Hydrological Programme. Kolkata, Geological Survey of India. (GSI Special Publication 34.)

Lorenzo, J.L. 1964. Los glaciares de México. Second edition. México, Universidad Nacional Autónoma de México. (Monografías del Instituto de Geofísica 1.)

Mool, P.K., D. Wangda, S.R. Bajracharya, K. Kuzang, D.R. Gurung and S.P. Joshi. 2001. Inventory of glaciers, glacial lakes and glacial lake outburst floods: monitoring and early warning systems in the Hindu Kush Himalayan region, Bhutan. Kathmandu, International Centre for Integrated Mountain Development.

Müller, F. 1978. Instructions for the compilation and assemblage of data for a world glacier inventory. Supplement: identification/ glacier number. Zürich, IAHS(ICSI)/UNEP/UNESCO. Temporary Technical Secretariat for the World Glacier Inventory. Swiss Federal Institute of Technology (ETH).

Müller, F., T. Caflisch and G. Müller 1977. Instructions for the compilation and assemblage of data for a world glacier inventory. Zürich, IAHS(ICSI)/UNEP/UNESCO. Temporary Technical Secretariat for the World Glacier Inventory. Swiss Federal Institute of Technology (ETH).

Ommanney, C.S.L. 1993. Yukon glaciers. In Prowse, T.D., C.S.L. Ommanney and K.E. Ulmer, eds. Proceedings of the Ninth International Northern Research Basins Symposium/ Workshop, 14-22 August 1992. Vol. 1. Saskatoon, Sask., Environment Canada. National Hydrology Research Institute, 373-382. (NHRI Symposium 10.)

Raper, S.C.B. and R.J. Braithwaite. 2006. Low sea level rise projections from mountain glaciers and icecaps under global warming. Nature, 439(7074), 311-313.

Rau, F., F. Mauz, S. Vogt, S.J.S. Khalsa and B. Raup. 2005. Illustrated GLIMS glacier classification manual: glacier classification guidance for the GLIMS inventory. Version 1. Freiburg, AlbertLudwigs-Universität. Institut für Physische Geographie; Boulder, CO, National Snow and Ice Data Center.

Raup, B., A. Racoviteanu, S.J.S. Khalsa, C. Helm, R. Armstrong and Y. Arnaud. 2007. The GLIMS geospatial glacier database: a new tool for studying glacier change. Global Planet. Change, 56(1-2), 101-110.

Sah, M., G. Philip, P.K. Mool, S. Bhajracharya and B. Shrestha. 2005. Uttaranchal Himalaya, India: inventory of glaciers and glacial lakes and the identification of potential glacial lake outburst floods (GLOFs) affected by global warming in the mountains of Himalayan Region. Kathmandu, International Centre for Integrated Mountain Development.

Scherler, K.E. 1983. Guidelines for preliminary glacier inventories. Zürich, ETH Zürich.

Sedov, R.V. 1997. Ledniki poluostrova Taygonos [Glaciers of the Taygonos Peninsula]. Mater. Glyatsiol. Issled. 82, 218-222. [In Russian with English summary.]

Svoboda, F. and F. Paul. 2009. A new glacier inventory on southern Baffin Island, Canada, from ASTER data: I. Applied methods, challenges and solutions. Ann. Glaciol., 50(53) (see paper in this issue). 
UNESCO/International Association of Scientific Hydrology (IASH). 1970. Perennial ice and snow masses: a guide for compilation and assemblage of data for a world inventory. Paris, UNESCO/ IASH. (Technical Papers in Hydrology 1, A2486.)

White, S.E. 2002. Glaciers of México. In Williams, R.S., Jr and J.G. Ferrigno, eds. Satellite image atlas of glaciers of the world. Denver, CO, US Geological Survey, J383-J405. (USGS Professional Paper 1386-J.)
World Glacier Monitoring Service (WGMS). 1989. World glacier inventory: status 1988, ed. Haeberli, W., H. Bösch, K. Scherler, G. Østrem, C.C. Wallén. IAHS(ICSI)/UNEP/UNESCO, World Glacier Monitoring Service, Zürich.

World Glacier Monitoring Service (WGMS). 1993. Fluctuations of glaciers 1985-1990 (Vol. VI), ed. Haeberli, W. and M. Hoelzle. IAHS/UNEP/UNESCO, World Glacier Monitoring Service, Zürich. 